\title{
Does parity matter in women's risk of dementia? A COSMIC collaboration cohort study
}

Jong Bin Bae ${ }^{1,2}$, Darren M. Lipnicki ${ }^{3}$, Ji Won Han ${ }^{1,2}$, Perminder S. Sachdev ${ }^{3,4}$, Tae Hui Kim, Kyung Phil Kwak ${ }^{6}$, Bong Jo Kim7, Shin Gyeom Kim², Jeong Lan Kim', Seok Woo Moon ${ }^{10}$, Joon Hyuk Park ${ }^{11}$, Seung-Ho Ryu' ${ }^{12}$, Jong Chul Youn ${ }^{13}$, Dong Young Lee ${ }^{2,14}$, Dong Woo Lee ${ }^{15}$, Seok Bum Lee ${ }^{16}$, Jung Jae Lee ${ }^{16}$, Jin Hyeong Jhoo ${ }^{17}$, Juan J. Llibre-Rodriguez ${ }^{18}$, Jorge J. Llibre-Guerra ${ }^{19,20}$, Adolfo J. Valhuerdi-Cepero ${ }^{21}$, Karen Ritchie ${ }^{22,23}$, Marie-Laure Ancelin ${ }^{22}$, Isabelle Carriere ${ }^{22}$, Ingmar Skoog ${ }^{24}$, Jenna Najar ${ }^{24}$, Therese Rydberg Sterner ${ }^{24}$, Nikolaos Scarmeas ${ }^{25,26}$, Mary Yannakoulia ${ }^{27}$, Efthimios Dardiotis ${ }^{28}$, Kenichi Meguro ${ }^{29}$, Mari Kasai ${ }^{29}, K^{24}$ Nakamura ${ }^{29}$, Steffi Riedel-Heller ${ }^{30}$, Susanne Roehr ${ }^{30}$, Alexander Pabst ${ }^{30}$, Martin van Boxtel ${ }^{31}$, Sebastian Köhler ${ }^{31}$, Ding Ding ${ }^{32,33}$, Qianhua Zhao ${ }^{32,33}$, Xiaoniu Liang ${ }^{32,33}$, Marcia Scazufca ${ }^{34}$, Antonio Lobo ${ }^{35,36,37}$, Concepción De-la-Cámara ${ }^{35,36,37}$, Elena Lobo $35,36,37$, Ki Woong Kim ${ }^{1,2,38^{*}}$ and for Cohort Studies of Memory in an International Consortium (COSMIC)

\section{Abstract}

Background: Dementia shows sex difference in its epidemiology. Childbirth, a distinctive experience of women, is associated with the risk for various diseases. However, its association with the risk of dementia in women has rarely been studied.

Methods: We harmonized and pooled baseline data from 11 population-based cohorts from 11 countries over 3 continents, including 14,792 women aged 60 years or older. We investigated the association between parity and the risk of dementia using logistic regression models that adjusted for age, educational level, hypertension, diabetes mellitus, and cohort, with additional analyses by region and dementia subtype.

(Continued on next page)

\footnotetext{
* Correspondence: kwkimmd@snu.ac.kr

'Department of Neuropsychiatry, Seoul National University Bundang Hospital, Seongnam, South Korea

${ }^{2}$ Department of Psychiatry, College of Medicine, Seoul National University, Seoul, South Korea

Full list of author information is available at the end of the article
}

(c) The Author(s). 2020 Open Access This article is licensed under a Creative Commons Attribution 4.0 International License, which permits use, sharing, adaptation, distribution and reproduction in any medium or format, as long as you give appropriate credit to the original author(s) and the source, provide a link to the Creative Commons licence, and indicate if changes were made. The images or other third party material in this article are included in the article's Creative Commons licence, unless indicated otherwise in a credit line to the material. If material is not included in the article's Creative Commons licence and your intended use is not permitted by statutory regulation or exceeds the permitted use, you will need to obtain permission directly from the copyright holder. To view a copy of this licence, visit http://creativecommons.org/licenses/by/4.0/ The Creative Commons Public Domain Dedication waiver (http://creativecommons.org/publicdomain/zero/1.0/) applies to the data made available in this article, unless otherwise stated in a credit line to the data. 


\begin{abstract}
(Continued from previous page)
Results: Across all cohorts, grand multiparous (5 or more childbirths) women had a $47 \%$ greater risk of dementia than primiparous (1 childbirth) women (odds ratio $[\mathrm{OR}]=1.47,95 \%$ confidence interval $[\mathrm{Cl}]=1.10-1.94$ ), while nulliparous (no childbirth) women and women with 2 to 4 childbirths showed a comparable dementia risk to primiparous women. However, there were differences associated with region and dementia subtype. Compared to women with 1 to 4 childbirths, grand multiparous women showed a higher risk of dementia in Europe $(\mathrm{OR}=2.99$, $95 \% \mathrm{Cl}=1.38-6.47)$ and Latin America $(\mathrm{OR}=1.49,95 \% \mathrm{Cl}=1.04-2.12)$, while nulliparous women showed a higher dementia risk in Asia $(\mathrm{OR}=2.15,95 \% \mathrm{Cl}=1.33-3.47)$. Grand multiparity was associated with 6.9-fold higher risk of vascular dementia in Europe $(\mathrm{OR}=6.86,95 \% \mathrm{Cl}=1.81-26.08)$, whereas nulliparity was associated with a higher risk of Alzheimer disease $(\mathrm{OR}=1.91,95 \% \mathrm{Cl} 1.07-3.39)$ and non-Alzheimer non-vascular dementia $(\mathrm{OR}=3.47,95 \% \mathrm{Cl}=$ 1.44-8.35) in Asia.
\end{abstract}

Conclusion: Parity is associated with women's risk of dementia, though this is not uniform across regions and dementia subtypes.

Keywords: Dementia, Alzheimer's disease, Risk factors, Parity, Women

\section{Background}

Dementia is one of many disorders with sex and gender differences in epidemiology, risk factors, and outcomes. Compared to men, women show a greater prevalence of dementia [1], a higher risk of Alzheimer disease (AD) conferred by the apolipoprotein $\varepsilon 4$ allele [2], and faster loss of autonomy after diagnosis of AD [3]. Pregnancy and childbirth are distinctive experiences of women and are associated with changes in hormone levels, health conditions, and lifestyle that influence the risk of dementia. For example, estrogen is closely associated with the risk of $\mathrm{AD}$ and vascular dementia $(\mathrm{VaD})[4]$, and its serum level increases more than 10-fold in the third trimester of pregnancy $[4,5]$. A higher number of births is generally associated with lower socioeconomical status and educational level, factors that may increase the risk of dementia [6]. Additionally grand multiparity (5 or more childbirths) increases the chances of developing hypertension, coronary heart disease, and diabetes mellitus (DM) [7-9], all of which can increase the risk of dementia.

Studies on whether parity affects the risk of dementia are limited, and their results are different according to study design and study population with different level of parity. Some research suggests that more childbirths increases the risk of dementia. A pooled analysis of two population-based cohorts from South Korea and Greece found that grand multiparous women had a 1.7-fold higher risk of $\mathrm{AD}$ than women with 1 to 4 childbirths [10], and a case-control study in Germany found that nulliparity was less frequent in women with $\mathrm{AD}$ than in cognitively normal women [11]. However, a prospective cohort study in Italy found nulliparous women to show a comparable risk of dementia to women with 1 to 4 childbirths [12], and an analysis of a claims database from the USA found that women with 3 or more childbirths showed a lower risk of dementia than women giving birth only once (primiparous) [13].
In this study, we used the pooled data of 11 population-based prospective cohort studies from 11 countries over 3 continents to investigate whether parity influences the risk of dementia, and whether there are differences associated with geographic region and type of dementia. Knowing whether parity affects the risk of dementia will help to clarify sex and gender difference in dementia and could identify a high-risk group in women. With such a diverse overall sample, our study might also help to explain the different results from previous studies.

\section{Methods \\ Study population}

We pooled baseline data for community-dwelling women aged 60 or older from 11 members of the Cohort Studies of Memory in an International Consortium (COSMIC) collaboration (Table 1) [14-25]. The participants were randomly sampled in all studies but the Maastricht Ageing Study (MAAS). Although the Leipzig Longitudinal Study of the Aged (LEILA 75+) included both community-dwelling and institutionalized participants, we included the community sample only in the present study. The included cohorts varied in size from 342 to 3919 participants. From an initial sample of 16, 296 women, we excluded 1504 who did not have data on educational level, hypertension, DM, or parity, giving a final sample of 14,792 women.

\section{Measures}

All studies provided data on dementia diagnosis, based on DSM-IV criteria [26] in 10 studies and DSM-III-R criteria [27] in one. Nine studies provided data on dementia subtypes: AD according to the NINCDS-ADRDA criteria [28] or DSM-IV criteria [26], and $\mathrm{VaD}$ according to the NINDS-AIREN criteria [29] or DSM-IV criteria [26]. 
Table 1 Contributing cohorts

\begin{tabular}{|c|c|c|c|c|c|c|c|}
\hline Study & Location & Start & Ethnicity* & $\begin{array}{l}\text { Participants }{ }^{\dagger} \text { (all/women/ } \\
\text { included) }\end{array}$ & $\mathrm{Age}^{\ddagger}$ & Parity $^{\ddagger}$ & $\begin{array}{l}\text { Dementia }^{\dagger} \\
\text { (all/AD/NaD) }\end{array}$ \\
\hline $\mathrm{CHAS}^{15}$ & Havana and Matanzas, Cuba & 2003 & Cuban & $2944 / 1913 / 1552$ & $75.1 \pm 7.2(65-100)$ & $2.5 \pm 2.2(0-23)^{c}$ & $183 / 105 / 11$ \\
\hline ESPRIT $^{16}$ & Montpellier, France & 1999 & White & 2259/1313/1094 & $72.5 \pm 5.6(65-93)$ & $2.4 \pm 1.5(0-9)^{\mathrm{cb}}$ & $19 / 17 / 1$ \\
\hline $\mathrm{H} 70^{17}$ & Gothenburg, Sweden & 2000 & White & $1016 / 787 / 575$ & $74.7 \pm 5.4(70-92)$ & $2.0 \pm 1.6(0-20)^{c}$ & $16 / 7 / 4$ \\
\hline HELIAD ${ }^{18}$ & Larissa and Marousi, Greece & 2009 & White & $1814 / 1074 / 918$ & $72.1 \pm 5.5(60-93)$ & $2.0 \pm 0.8(0-7)^{\mathrm{cb}}$ & $22 / 16 / 3$ \\
\hline $\mathrm{KLOSCAD}^{19}$ & Nationwide, South Korea & 2010 & Asian & $6818 / 3919 / 3686$ & $70.7 \pm 7.2(60-101)$ & $3.6 \pm 1.7(0-12)^{\mathrm{cb}}$ & $190 / 145 / 17$ \\
\hline $\mathrm{KS}^{20}$ & Kurihara, Japan & 2008 & Asian & $590 / 365 / 365$ & $80.3 \pm 4.2(74-94)$ & $2.4 \pm 1.3(0-7)^{\mathrm{cb}}$ & $49 / 32 / 3$ \\
\hline LEILA $75+{ }^{21}$ & Leipzig, Germany & 1997 & White & $1265 / 964 / 636$ & $81.2 \pm 4.9(75-99)$ & $1.6 \pm 1.3(0-10)^{c}$ & $68 / 48 / 14$ \\
\hline MAAS $^{22}$ & South Limburg, Netherlands & 1993 & White & $683 / 342 / 342$ & $69.2 \pm 6.2(60-82)$ & $2.6 \pm 1.9(0-9)^{c}$ & 26/n.a./n.a. \\
\hline $\mathrm{SAS}^{23}$ & Shanghai, China & 2010 & Asian & $3141 / 1873 / 1869$ & $71.2 \pm 8.4(60-100)$ & $2.0 \pm 1.4(0-9)^{\mathrm{cb}}$ & $97 / 67 / 7$ \\
\hline $\mathrm{SPAH}^{24}$ & Sao Paulo, Brazil & 2003 & Brazilian & 2072/1255/1149 & $72.6 \pm 6.4(65-101)$ & $5.6 \pm 4.1(0-24)^{c}$ & $68 / 24 / 13$ \\
\hline ZARADEMP 25 & Zaragoza, Spain & 1994 & White & $4638 / 2683 / 2606$ & $74.5 \pm 9.6(60-102)$ & $2.4 \pm 1.9(0-12)^{\mathrm{cb}}$ & 152/n.a./n \\
\hline
\end{tabular}

CHAS Cuban Health and Alzheimer Study, ESPRIT Etude SanteÂ Psychologique et Traitement, H70 Gothenburg H70 Birth Cohort Studies, HELIAD Hellenic Longitudinal Investigation of Aging and Diet, KLOSCAD Korean Longitudinal Study on Cognitive Aging and Dementia, KS Kurihara Study, LEILA75+ Leipzig Longitudinal Study of the Aged, MAAS Maastricht Ageing Study, SAS Shanghai Aging Study, SPAH Sao Paulo Ageing \& Health Study, ZARADEMP Zaragoza Dementia Depression Project, $A D$ Alzheimer's disease, $V a D$ vascular dementia, n.a. not available

The participants of all studies but MAAS were randomly sampled.

*Ethnicity of the country

${ }^{+}$Numbers at the baseline assessment

${ }^{\ddagger}$ Mean \pm standard deviations (range)

cNumber of children

${ }^{\mathrm{cb}}$ Number of childbirths

Other data included parity, age, sex, educational level, and presence of hypertension and DM which were all harmonized when necessary. We assigned parity as the number of childbirths in 6 cohorts and as the number of children in 5 cohorts. When the participants adopted and fostered children or their children died after birth, the number of childbirths and children could be different. However, only 3 among 590 women (0.3\%) had different numbers for childbirths and children in Kurihara study (KS) providing numbers for both childbirths and children, and we used data on childbirth in these 3 cases. To harmonize data on educational level, we classified it into 3 categories. For nine studies with data on years of education, we classified educational level as $\leq 6,7$ to 12 , or $>12$ years. Three comparable education level groups were used for the remaining two studies with categorical data: primary school or under, secondary school, and tertiary school or above. For hypertension and DM, we used all available information from a study relevant to diagnosing or classifying the condition. In a study with limited information, hypertension and DM may be classified only from a medical history record, while for another study, it may be indicated by any of self-reported history, use of relevant medication, or measured blood pressure or glucose level exceeding values indicated by international guidelines. Four studies (Cuban Health and Alzheimer Study [CHAS], Hellenic Longitudinal Investigation of Aging and Diet [HELIAD], Korean Longitudinal Study on Cognitive Aging and Dementia [KLOSCAD] and Sao Paulo Ageing \& Health Study [SPAH]) additionally provided data on economic status, employment, and length of reproductive years. Low economic status was defined as lower $50 \%$ based on assets in the CHAS, less than KRW 1,000,000 of monthly house income in the KLOSCAD, and BRL 360 or less of monthly house income in the SPAH. In the HELIAD, 4 socioeconomic variables regarding a set of economic reserves or assets, holiday travelling, and leisure time activities were used to define low economic status [30]. Unemployment was defined as "never been employed in lifetime" in all cohorts. The length of reproductive years was calculated by subtracting the age at menarche from the age at menopause.

\section{Analysis}

We initially examined the association between parity $(0$, $2,3,4, \geq 5$ vs 1 ) and the risk of all-cause dementia with unadjusted and adjusted binary logistic regressions. The adjusted model included age, educational level, hypertension, DM, and cohort as covariates. We employed primiparous women as the reference instead of nulliparous women because nulliparity is associated with earlier menopause [31], and women with earlier menopause had an increased risk of dementia [32]. In obstetrics, 5 or more parities and 10 or more parities are defined as grand multiparity and great grand multiparity, respectively, and they were known to increase obstetric and neonatal complications [33]. Because the number of women with 5 or more births was relatively low, we did not analyze each number of births from 5 or more separately, but rather grouped them into a grand multiparity group. In addition, we 
further classified grand multiparous women who gave 10 or more childbirths as a great grand multiparity group to examine whether an extremely higher number of parity additionally increase the risk of dementia. Next, we collapsed women with 1 to 4 parities into a referent group and compared this against nulliparity and grand multiparity using the adjusted analyses described above. For 4 cohorts with the additional data, we conducted analyses that further adjusted for socioeconomic status, employment, and reproductive years. We also used adjusted logistic regression to investigate the association between parity as a continuous variable and the risk of all-cause dementia.

The effects of parity and geographic region, and their interaction, on the risk of all-cause dementia were investigated using a binary logistic regression. In this analysis, we grouped parity into nulliparity, 1 to 4 parities, and grand multiparity, and geographic region into Asia, Europe, and Latin America. We adjusted for age, educational level, hypertension, and DM.

We also conducted analyses within each geographic region that examined how both nulliparity and grand multiparity (vs 1 to 4 parities) were associated with (1) the risk of all-cause dementia, using binary logistic regressions, and (2) the risks of $\mathrm{AD}, \mathrm{VaD}$, and nonAlzheimer non-vascular dementia (NAVD), using multinomial logistic regressions. These analyses used data from the 9 cohorts with information on dementia subtype. We excluded individuals with mixed etiologies (2.5\% of dementia) and adjusted for age, educational level, hypertension, DM, and cohort.

The KLOSCAD team harmonized and pooled the dataset and performed the analyses using the Statistical Package for Social Sciences, v20 (SPSS Inc., Chicago, IL).

\section{Results}

The characteristics of the contributing cohorts are summarized in Table 1. At least $10 \%$ of women were grand multiparous in 5 cohorts and nulliparous in 4 cohorts. Grand multiparity was more frequent in the Latin American cohorts (28.6\%) than in the Asian (17.8\%) and European (7.8\%) cohorts. The Asian cohorts had less frequent nulliparity (4.5\%) than the European (14.3\%) and Latin American (11.2\%) cohorts (Table 2). The prevalence of dementia was also different between regions. The frequency of dementia was $10 \%$ or more in 3 cohorts, and higher in the Latin American cohorts compared to the Asian and European cohorts $(P<0.01)$. When the prevalence of dementia subtypes was compared separately, AD was less prevalent in the Asian cohorts compared to the European and Latin American cohorts while NAVD was more prevalent in the Latin American cohorts compared to the Asian and European cohorts $(P<0.01)$. Compared to women with 1 to 4 parities, grand multiparous women were older $(72.3 \pm 7.7$ years vs $75.6 \pm 7.6$ years, $P<0.01)$, showed higher proportion of only primary or less education $(44 \%$ vs $80 \%$, $P<0.01)$, and had more hypertension $(65 \%$ vs $71 \%, P<$ $0.01)$ and $\mathrm{DM}(17 \%$ vs $24 \%, P<0.01)$.

The number of parities was associated with hypertension and DM (Table 3). Compared to women with 1 to 4 parities, grand multiparous women were more likely to have hypertension and DM $(P<0.01)$ and nulliparous women showed a higher frequency of hypertension and lower frequency of DM $(P<0.01)$.

Table 4 shows the risk of all-cause dementia associated with parity determined with our initial analyses. In the unadjusted logistic regression model, the risk of allcause dementia was not significantly different for nulliparous women and women with 2,3, or 4 parities, but was significantly higher for grand multiparous women compared to primiparous women. In the logistic regression model adjusting for age, educational level, and cohort, grand multiparous women showed 1.47-fold higher risk of all-cause dementia than primiparous women (95\% confidence interval $[\mathrm{CI}]=1.11-1.94, \quad P<0.01$ ). When we further adjusted for hypertension and DM, the association between grand multiparity and the risk for all-cause dementia remained significant $(\mathrm{OR}=1.47,95 \%$ $\mathrm{CI}=1.10-1.94, P<0.01)$. When we divided grand multiparous women into two groups, women with 5 to 9 parities and great grand multiparous women showed 1.44-fold (95\% CI $=1.08-1.90, P=0.01)$ and 1.86 -fold (95\% CI $=1.11-3.09, P=0.02$ ) higher risks of all-cause dementia, respectively. Further analyses with 1 to 4 parities as the reference group found the risk of all-cause dementia to be significantly higher in grand multiparous women (odds ratio $[\mathrm{OR}]=1.33,95 \% \mathrm{CI}=1.09-1.60, P<$ 0.01 ) but not significantly different in nulliparous women $(\mathrm{OR}=0.83,95 \% \mathrm{CI}=0.64-1.08, P=0.16)$. The results were similar when additionally adjusting for economic status, employment, and reproductive years; grand multiparity was associated with an increased risk of all-cause dementia $(\mathrm{OR}=1.46,95 \% \mathrm{CI}=1.13-1.89$, $P<0.01)$, but nulliparity was not $(\mathrm{OR}=1.07,95 \% \mathrm{CI}=$ $0.70-1.62, P=0.77$ ). An analysis with parity as a continuous variable showed the risk of all-cause dementia to increase as the number of parities increased $(\mathrm{OR}=1.06$, 95\% CI $=1.03-1.10, P<0.01$ ).

In further analyses, the risk of all-cause dementia was significantly associated with parity $(P<0.01)$ and geographic region $(P<0.01)$, as well as their interaction $(P<0.01)$. As seen in Table 5, compared to women with 1 to 4 parities, grand multiparous women showed about 3-fold and 1.5fold higher risk of all-cause dementia in the European $(P<$ $0.01)$ and Latin American $(P=0.03)$ cohorts. Grand multiparous women also showed a modestly higher risk of allcause dementia in the Asian cohorts, but this was not statistically significant $(P=0.24)$. Nulliparous women 
Table 2 Comparison of the cohort characteristics between three geographical regions

\begin{tabular}{|c|c|c|c|c|c|c|c|}
\hline \multirow[t]{2}{*}{ Characteristics } & \multirow{2}{*}{$\begin{array}{l}\text { Total } \\
(N=14,792)\end{array}$} & \multirow{2}{*}{$\begin{array}{l}\text { Asia } \\
(N=5920)\end{array}$} & \multirow{2}{*}{$\begin{array}{l}\text { Europe } \\
(N=6171)\end{array}$} & \multirow{2}{*}{$\begin{array}{l}\text { Latin America } \\
(N=2701)\end{array}$} & \multicolumn{3}{|l|}{ Statistics* } \\
\hline & & & & & $\overline{F o r} x^{2}$ & $P$ & Post hoc* \\
\hline Age, mean $\pm S D$, years & $73.1 \pm 7.9$ & $71.4 \pm 7.8$ & $74.2 \pm 8.0$ & $74.0 \pm 7.0$ & 217.79 & $<0.001$ & $a<b, a<c$ \\
\hline Educational level, \% & & & & & 1049.72 & $<0.001$ & - \\
\hline$\leq 6$ years or primary school or under & 48.8 & 46.6 & 39.4 & 75.0 & & & \\
\hline 7 to 12 years or secondary school & 38.8 & 39.0 & 48.4 & 16.1 & & & \\
\hline$>12$ years or tertiary school or above & 12.5 & 14.4 & 12.2 & 12.2 & & & \\
\hline Hypertension, \% & 66.5 & 55.7 & 71.2 & 79.2 & 569.22 & $<0.001$ & $a<b, a<c, b<c$ \\
\hline Diabetes mellitus, $\%$ & 17.3 & 16.6 & 12.7 & 29.5 & 375.205 & $<0.001$ & $a>b, a<c, b<c$ \\
\hline Parity (continuous), mean \pm SD & $2.8 \pm 2.2$ & $3.0 \pm 1.8$ & $2.3 \pm 1.6$ & $3.8 \pm 3.5$ & 512.99 & $<0.001$ & $a>b, a<c, b<c$ \\
\hline Parity (categorical), \% & & & & & 949.73 & $<0.001$ & \\
\hline 0 (nulliparity) & 9.8 & 4.5 & 14.3 & 11.2 & & & \\
\hline 1 to 4 & 74.6 & 77.8 & 77.9 & 60.2 & & & \\
\hline$\geq 5$ (grand multiparity) & 15.6 & 17.8 & 7.8 & 28.6 & & & \\
\hline Dementia prevalence, $\%$ & 5.9 & 5.7 & 4.7 & 9.1 & 64.60 & $<0.001$ & $a<c, b<c$ \\
\hline Dementia subtypes, ${ }^{\dagger} \%$ & & & & & 54.14 & $<0.001$ & - \\
\hline$A D$ & 4.0 & 3.1 & 4.1 & 4.8 & & & \\
\hline VD & 0.6 & 0.7 & 0.5 & 0.9 & & & \\
\hline NAVD & 1.4 & 0.4 & 0.9 & 3.3 & & & \\
\hline
\end{tabular}

SD standard deviation, $A D$ Alzheimer's disease, VaD vascular dementia, NAVD non-Alzheimer non-vascular dementia

*Continuous variables were compared using analysis of variance, and categorical variables were compared using the $x^{2}$ test. Post hoc comparisons were based on Scheffé's theorem: $a=$ Asia; $b=$ Europe; $c=$ Latin America

${ }^{\dagger}$ Estimated using 9 cohorts providing data on dementia subtypes

showed about 2-fold higher risk of all-cause dementia than women with 1 to 4 parities in the Asian cohorts $(P<0.01)$, but associations with nulliparity were not statistically significant in the European $(P=0.66)$ and Latin American $(P=0.26)$ cohorts.
The results of analyses examining how grand multiparity and nulliparity were associated with the risks of $\mathrm{AD}$, $\mathrm{VaD}$, and NAVD separately in each geographic region are also shown in Table 5. Compared to women with 1 to 4 parities, grand multiparity was associated with a

Table 3 Comparison of the cohort characteristics between three parity groups

\begin{tabular}{|c|c|c|c|c|c|c|}
\hline \multirow[t]{2}{*}{ Characteristics } & \multicolumn{3}{|c|}{ Number of parities } & \multicolumn{3}{|l|}{ Statistics* } \\
\hline & $\overline{0}$ & 1 to 4 & $\geq 5$ & $\overline{F o r} X^{2}$ & $P$ & Post hoc* \\
\hline Age, mean $\pm S D$, years & $74 \pm 8.3$ & $72.3 \pm 7.7$ & $75.6 \pm 7.7$ & 224.345 & $<0.001$ & $a>b, a<c, b<c$ \\
\hline Educational level, \% & & & & 1122.978 & $<0.001$ & - \\
\hline$\leq 6$ years or primary school or under & 36.5 & 43.9 & 80.0 & & & \\
\hline 7 to 12 years or secondary school & 44.4 & 42.6 & 17.1 & & & \\
\hline$>12$ years or tertiary school or above & 19.1 & 13.6 & 2.9 & & & \\
\hline Hypertension, \% & 69.3 & 65.2 & 70.9 & 33.289 & $<0.001$ & $a>b, b<c$ \\
\hline Diabetes mellitus, \% & 13.1 & 16.5 & 23.5 & 84.376 & $<0.001$ & $a<b, a<c, b<c$ \\
\hline Dementia prevalence, \% & 5.8 & 5.0 & 10.5 & 103.961 & $<0.001$ & $\mathrm{a}<\mathrm{c}, \mathrm{b}<\mathrm{c}$ \\
\hline Dementia subtypes, ${ }^{\dagger} \%$ & & & & 112.556 & $<0.001$ & - \\
\hline$A D$ & 4.6 & 3.1 & 7.1 & & & \\
\hline VD & 0.6 & 0.5 & 1.1 & & & \\
\hline NAVD & 2.2 & 1.0 & 2.4 & & & \\
\hline
\end{tabular}

*Continuous variables were compared using analysis of variance, and categorical variables were compared using the $x^{2}$ test. Post hoc comparisons were based on Scheffé's theorem: $a=$ nulliparity; $b=1$ to 4 parities; $c=$ grand multiparity

${ }^{\dagger}$ Estimated using 9 cohorts providing data on dementia subtypes 
Table 4 The risk of all-cause dementia associated with parity

\begin{tabular}{|c|c|c|c|c|c|c|c|c|}
\hline \multirow[t]{2}{*}{ Parity } & \multicolumn{2}{|c|}{ Number of subjects } & \multicolumn{2}{|c|}{ Unadjusted model } & \multicolumn{2}{|c|}{ Adjusted model I* } & \multicolumn{2}{|c|}{ Adjusted model $\|^{\dagger}$} \\
\hline & Control & Dementia & OR $(95 \% \mathrm{Cl})$ & $P$ & OR $(95 \% \mathrm{Cl})$ & $P$ & OR $(95 \% \mathrm{Cl})$ & $P$ \\
\hline 0 (nulliparity) & 1368 & 84 & $1.25(0.93-1.68)$ & 0.014 & $0.91(0.66-1.25)$ & 0.560 & $0.92(0.67-1.27)$ & 0.613 \\
\hline 1 (primiparity) & 2096 & 103 & 1.00 [Reference] & & 1.00 [Reference] & & 1.00 [Reference] & \\
\hline 2 & 3923 & 181 & $0.94(0.73-1.20)$ & 0.618 & $1.12(0.86-1.46)$ & 0.397 & $1.13(0.86-1.47)$ & 0.375 \\
\hline 3 & 2819 & 161 & $1.16(0.90-1.50)$ & 0.245 & $1.19(0.91-1.57)$ & 0.206 & $1.19(0.91-1.57)$ & 0.200 \\
\hline 4 & 1652 & 103 & $1.27(0.96-1.68)$ & 0.096 & $1.06(0.79-1.44)$ & 0.690 & $1.07(0.79-1.45)$ & 0.664 \\
\hline$\geq 5$ (grand multiparity) & 2061 & 241 & $2.38(1.87-3.02)$ & $<0.001$ & $1.47(1.11-1.94)$ & 0.007 & $1.47(1.10-1.94)$ & 0.007 \\
\hline 5 to 9 & 1836 & 212 & $2.35(1.84-3.00)$ & $<0.001$ & $1.43(1.08-1.90)$ & 0.012 & $1.44(1.08-1.90)$ & 0.012 \\
\hline$\geq 10$ & 225 & 29 & $2.62(1.70-4.05)$ & $<0.001$ & $1.84(1.11-3.06)$ & 0.019 & $1.86(1.11-3.09)$ & 0.018 \\
\hline
\end{tabular}

$O R$ odds ratio, $\mathrm{Cl}$ confidence intervals

*Binary logistic regression analyses adjusted for age, educational level, and cohort as covariates

${ }^{\dagger}$ Binary logistic regression analyses adjusted for age, educational level, hypertension, diabetes mellitus, and cohort as covariates

more than 6-fold higher risk of $\mathrm{VaD}$ in the European cohorts $(P<0.01)$ and about a 1.8 -fold higher risk of NAVD in the Latin American cohorts $(P=0.03)$. Nulliparity was associated with about a 1.9-fold higher risk of AD $(P=0.03)$ and about a 3.5-fold higher risk of NAVD $(P<0.01)$ in the Asian cohorts. However, the associations between nulliparity and the risk of $\mathrm{AD}, \mathrm{VaD}$, and NAVD were not statistically significant in other geographic regions.

\section{Discussion}

This study included nearly 15,000 community-dwelling elderly women from 11 population-based prospective cohort studies from 11 countries over 3 continents and found that grand multiparity and nulliparity were associated with an increased risk of dementia. However, these associations were not uniform across different geographic regions or dementia subtypes. Grand multiparity was associated with an increased risk of $\mathrm{VaD}$ in European cohorts and an increased risk of NAVD in Latin American cohorts. Conversely, nulliparity was associated with an increased risk of both AD and NAVD in Asian cohorts.

The association between grand multiparity and the risk of all-cause dementia has not been previously investigated. Gilsanz et al., using a claims database that included 14,595 women (Caucasian 68\%, African American $16 \%$, Asian 6\%, and Hispanic 5\%), reported that women with 3 or more childbirths showed modestly lower risk of all-cause dementia (hazard ratio $=0.88$, 95\% $\mathrm{CI}=0.81-0.95)$ than primiparous women [13]. However, they did not specifically analyze the association between grand multiparity and the risk of all-cause dementia, and their dementia diagnoses were derived from the billing codes of electronic medical records, which may lack diagnostic accuracy [34]. Their results thus cannot be directly compared against our finding that grand multiparity increased the risk of dementia. It has been previously reported that grand multiparous women are more likely to have risk factors for dementia that include being less educated, unemployed, and economically disadvantaged [6], experiencing more stress during childbearing, and higher rates of medical conditions such as coronary heart disease, stroke, DM, and metabolic syndrome [7-9]. This is consistent with the data we had showing less education and higher rates of hypertension and DM in grand multiparous women. Repetitive pregnancies and childbirths may also have direct cumulative harmful effects on the brain. For example, serum estradiol increases more than 10-fold and insulin sensitivity drops to $50 \%$ in the third trimester, with both effects potentially neurotoxic $[35,36]$. Gray matter volumes in multiple areas including the hippocampus were reduced and persisted for 2 years after birth [37]. Density and numbers of microglia which is known to contribute to neurogenesis and spinogenesis were reduced during peripartum period, and its proliferation was reduced in the postpartum hippocampus [38]. In addition, serum estrogen was reduced after pregnancy in both premenopausal and postmenopausal periods [39, 40].

The number of people with dementia is expected to more than double in Africa, Asia, and Latin America, and the global proportion of individuals with dementia living in these regions will have increased to about $70 \%$ by 2050 [41]. Women in these regions have typically had much higher fertility rates than women in Europe and North America [42]. Despite the global fertility rate having fallen by half in the last 60 years or so (from 5 to 2.5 births per woman), it remains at around five in most African countries [41]. While this suggests that grand multiparity may be a risk factor for dementia of particular importance to Africa, further research is needed given our lack of African cohorts and findings of geographic differences.

Although grand multiparity was associated with an increased risk of dementia both in European and Latin 


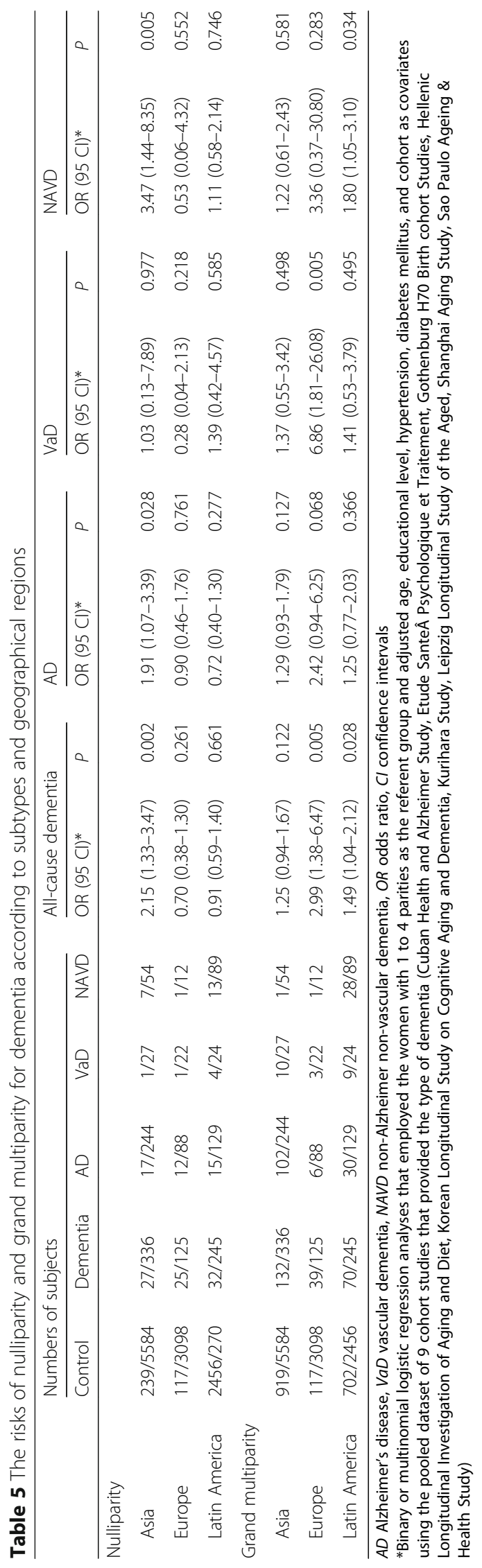


American cohorts, the association was not significant in Asian cohorts. There were also differences associated with dementia subtype. Grand multiparity was associated with a more than 6-fold higher risk of $\mathrm{VaD}$ in European cohorts, and about a 2-fold risk of NAVD in Latin American cohorts. Different associations between grand multiparity and dementia risk by geographic region and dementia subtype might be due to different ethno-racial susceptibilities of the hormonal and vascular system to the effects of pregnancy or childbirth. For example, it has been previously reported that the number of parities influenced gestational period estradiol levels in Caucasian women, but not in Asian women [43], and that the risks of gestational hypertension and preeclampsia were higher in Caucasian women than in Asian/Pacific Islanders and Hispanic women [44]. Insulin resistance, which was more prevalent in postmenopausal women with 4 or more children compared to those with $0-3$ parities [45], may influence the risk of dementia in European regions where DM was less prevalent compared to the Asian and Latin American regions. Although we could not adjust the effect of apolipoprotein E genotype in the present study, different distribution of apolipoprotein $\mathrm{E}$ genotype and psychosocial stresses associated with childbearing between regions may possibly contribute to the different association between grand multiparity and the risk of dementia between regions.

In contrast to grand multiparity being associated with an increased risk of dementia in both the European and Latin American cohorts, only in Asian cohorts was nulliparity associated with a higher risk of dementia, particularly non-vascular dementia. In the current study, the proportion of $\mathrm{VaD}$ in all-cause dementia was higher in the European cohorts (18\%) than in Asian (8.3\%) and Latin American (9.9\%) cohorts. This inter-regional difference in the association between nulliparity and the risk of dementia may be, at least in part, attributable to an inter-regional difference in the causes of nulliparity. In the current study, the proportion of nulliparous women in Asian cohorts (4.5\%) was much lower than that in European (14.3\%) and Latin American (11.2\%) cohorts, and nonmarriage and voluntary childlessness in nulliparous women are less common in Asian countries compared to the Western countries [46]. Therefore, nulliparous women in Asia are more likely to have involuntary factors as causes of nulliparity. The majority of involuntary causes of nulliparity are infertility and recurrent miscarriage. The most common cause of infertility is ovulatory dysfunction caused by premature ovarian failure, ovarian hyperandrogenism, hypothalamic dysfunction, pituitary disease, and thyroid disease [47], and these conditions are reportedly associated with the risk of cognitive impairment or AD [48]. Furthermore, women experiencing recurrent miscarriage are more likely to have the apolipoprotein $\mathrm{E} \varepsilon 4$ allele, which conveys an increased risk of $\mathrm{AD}$ [49].

The current study has limitations. First, we could not adjust for some well-known associated factors for dementia such as apolipoprotein E genotype, diet, reproductive experiences such as breast feeding, and gynecological surgery that could be associated with parity. However, in our previous work, the association between parity and AD remained significant even after adjusting for breast feeding, history of hormonal replacement therapy, hysterectomy, and oophorectomy [10]. Second, the data harmonization procedure might have confounded our observations. For example, parity data was based on the number of childbirths in 6 cohorts and the number of children in 5 cohorts, and adoption or death of children might have distorted parity information. However, this would likely apply to only a very small number of cases, given that for our KS, only $0.3 \%$ of women had different numbers for childbirths and children. Third, information on parity was obtained retrospectively. However, childbirths are life events not easily forgotten and likely to be minimally prone to recall bias. Fourth, regional difference in the diagnostic rates of dementia and its subtypes might have influenced the differential associations of parity with dementia subtypes according to geographical regions because the prevalence of dementia subtypes was considerably different between geographical regions. Fifth, women with middle- and late-stage dementia might be less likely to be included in the present study because all participants were community-dwelling.

\section{Conclusions}

Grand multiparity and nulliparity are associated with the risk of dementia in women, but these associations were not uniform across geographic regions and dementia subtypes. The findings of this study help to understand the development of dementia in women, and have important implications for world regions where the birth rate remains high.

\section{Abbreviations \\ AD: Alzheimer disease; CHAS: Cuban Health and Alzheimer Study; Cl: Confidence interval; COSMIC: Cohort Studies of Memory in an International Consortium; DM: Diabetes mellitus; ESPRIT: Etude SantêA Psychologique et Traitement; H70: Gothenburg H70 Birth Cohort Studies; HELIAD: Hellenic Longitudinal Investigation of Aging and Diet; KLOSCAD: Korean Longitudinal Study on Cognitive Aging and Dementia; KS: Kurihara Study; LEILA75+: Leipzig Longitudinal Study of the Aged; MAAS: Maastricht Ageing Study; NAVD: Non-Alzheimer non-vascular demen- tia; OR: Odds ratio; SAS: Shanghai Aging Study; SPAH: Sao Paulo Ageing \& Health Study; VaD: Vascular dementia; ZARADEMP: Zaragoza Dementia Depression Project}

Acknowledgements

The Sydney COSMIC team comprises Perminder S. Sachdev (head of COSMIC, and joint study leader of the Sydney Memory and Ageing Study), Darren M. Lipnicki (COSMIC study co-ordinator), Steve R Makkar, John D 
Crawford, Anbupalam Thalamuthu, Nicole A. Kochan, Yvonne Leung, and Jessica W. Lo.

Affiliations of the authors with the contributing studies are as follows (asterisk indicates study leader or joint study leader):

Cuban Health and Alzheimer Study: Juan J. Llibre-Rodriguez*, Jorge J. LlibreGuerra, Adolfo J. Valhuerdi-Cepero;

Etude Santé Psychologique et Traitement: Karen Ritchie*, Marie-Laure Ancelin*, Isabelle Carrière;

Gothenburg H70 Birth cohort Studies: Ingmar Skoog*, Jenna Najar, Therese

Rydberg Sterner;

Hellenic Longitudinal Investigation of Aging and Diet: Nikolaos Scarmeas*, Mary Yannakoulia, Efthimios Dardiotis;

Korean Longitudinal Study on Cognitive Aging and Dementia: Ki Woong

Kim*, Ji Won Han, Jong Bin Bae;

Kurihara Study: Kenichi Meguro*, Mari Kasai, Kei Nakamura;

Leipzig Longitudinal Study of the Aged: Steffi G. Riedel-Heller*, Susanne

Roehr, Alexander Pabst;

Maastricht Ageing Study: Martin van Boxtel*, Sebastian Köhler*;

Shanghai Aging Study: Ding Ding*. Qianhua Zhao, Xiaoniu Liang;

São Paulo Ageing \& Health Study: Marcia Scazufca*;

Zaragoza Dementia Depression Project: Antonio Lobo*, Concepción De-laCámara, Elena Lobo.

Further COSMIC study leaders: Yuda Turana (Atma Jaya Cognitive \& Aging Research), Erico Castro-Costa (Bambui Cohort Study of Aging), Bagher Larijani and Iraj Nabipour (Bushehr Elderly Health Program), Kenneth Rockwood (Canadian Study of Health \& Aging), Xiao Shifu (Chinese Longitudinal Aging Study), Richard B. Lipton and Mindy J. Katz (Einstein Aging Study), PierreMarie Preux and Maëlenn Guerchet (Epidemiology of Dementia in Central Africa), Linda Lam (Hong Kong Memory and Ageing Prospective Study), Ingmar Skoog (Gothenburg H70 Birth Cohort Studies), Toshiharu Ninimiya (Hisayama Study), Richard Walker (Identification and Intervention for Dementia in Elderly Africans study), Hugh Hendrie (Indianapolis Ibadan Dementia Project), Antonio Guaita (Invecchiamento Cerebrale in Abbiategrasso), Liang-Kung Chen (ILan Longitudinal Aging Study), Suzana Shahar (LRGS TUA: Neuroprotective Model for Healthy Longevity among Malaysian Older Adults), Jacqueline Dominguez (Marikina Memory and Aging Project), Murali Krishna (Mysore studies of Natal effects on Ageing and Health), Mary Ganguli (Monongahela Valley Independent Elders Survey), Kaarin J. Anstey (Personality and Total Health Through Life Project), Michael Crowe (Puerto Rican Elderly: Health Conditions study), Mary N. Haan (Sacramento Area Latino Study on Aging), Shuzo Kumagai (Sasaguri Genkimon Study), Tze Pin Ng (Singapore Longitudinal Ageing Studies (I)), Henry Brodaty (Sydney Memory and Ageing Study), Kenichi Meguro (Tajiri Project), Richard Mayeux and Nicole Schupf (Washington Heights Inwood and Columbia Aging Project).

COSMIC NIH grant investigators: Perminder Sachdev: Scientia Professor of Neuropsychiatry; Co-Director, Centre for Healthy Brain Ageing (CHeBA), UNSW Sydney; Director, Neuropsychiatric Institute, Prince of Wales Hospital, Sydney, Australia. Mary Ganguli: Professor of Psychiatry, Neurology, and Epidemiology, University of Pittsburgh. Ronald Petersen: Professor of Neurology; Director, Mayo Clinic Alzheimer's Disease Research Center and the Mayo Clinic Study of Aging. Richard Lipton: Edwin S. Lowe Professor and Vice Chair of Neurology, Albert Einstein College of Medicine. Karen Ritchie: Professor and Director of the Neuropsychiatry Research Unit of the French National Institute of Research (INSERM U1061). Ki-Woong Kim: Professor of Brain and Cognitive Sciences, Director of National Institute of Dementia of Korea. Louisa Jorm: Director, Centre for Big Data Research in Health and Professor, Faculty of Medicine, UNSW Sydney, Australia. Henry Brodaty: Scientia Professor of Ageing \& Mental Health; Co-Director, Centre for Healthy Brain Ageing (CHeBA), UNSW Sydney; Director, Dementia Collaborative Research Centre (DCRC); Senior Consultant, Old Age Psychiatry, Prince of Wales Hospital.

\section{Authors' contributions}

KWK had full access to all the data in the study and was responsible for the decision to submit for publication. Study concept and design: KWK, JBB, and DML. Acquisition of data: JWH, KWK, THK, KPK, BJK, SGK, JLK, SWM, JHP, S-HR, $J C Y, D Y L, D W L, S B L, J J L, J H J, J J L-R, J J L-G, A J V-C, K R, M-L A, I C, I S, J N$, TRS, NS, $M Y, E D, K M, M K, K N, S R-H, S R, A P, M V B, S K, D D, Q Z, X L, M S, A L, C D$, and EL. Analysis and interpretation of data: KWK and JBB. Drafting of the manuscript: KWK, JBB, WJH, DML, and PSS. Critical revision of the manuscript for important intellectual content: all authors. All authors read and approved the final manuscript.

\section{Funding}

Funding for COSMIC comes from a National Health and Medical Research Council of Australia Program Grant (ID 1093083), the National Institute On Aging of the National Institutes of Health under Award Number RF1AG057531, and philanthropic contributions to The Dementia Momentum Fund (UNSW Project ID PS38235). Funding for the contributing studies is as follows:

CHAS: the Wellcome Trust Foundation (GR066133 and GR08002) and the Cuban Ministry of Public Health;

ESPRIT: Novartis; an unconditional grant from Novartis and from the National Research Agency (ANR Project 07 LVIE004).

H70: The Swedish Research Council (2015-02830, 2013-8717), Swedish Research Council for Health, Working Life and Welfare (2013-2300, 20132496), the Swedish state under the agreement between the Swedish government and the county councils, the ALF-agreement (ALF-716681), Alzheimerfonden, Hjärnfonden, The Alzheimer's Association Stephanie B. Overstreet Scholars (IIRG-00-2159), The Alzheimer's Association Zenith Award (ZEN-013151)

HELIAD: IIRG-09133014 from the Alzheimer's Association; 189 10276/8/9/2011 from the ESPA-EU program Excellence Grant (ARISTEIA), which is co-funded by the European Social Fund and Greek National resources, and $\Delta \curlyvee 2 \beta$ / OIK.51657/14.4.2009 from the Ministry for Health and Social Solidarity (Greece);

KLOSCAD: the Korean Health Technology R\&D Project, Ministry of Health and Welfare, Republic of Korea [Grant No. HI09C1379 (A092077)];

KS: The Kurihara-funded research 2008-2010 and the Japanese Ministry of Health, Labour and Welfare 2009-2010.

LEILA75+: the Interdisciplinary Centre for Clinical Research at the University of Leipzig (Interdisziplinäres Zentrum für Klinische Forschung/IZKF; grant 01KS9504);

MAAS: Supported by grants from the Maastricht University Medical Center, the School for Mental Health and Neuroscience and the Dutch Ministry for Education, Culture and Science via the Netherlands Program for Research on Aging (NESTOR)

SAS: Shanghai Brain-Intelligence Project [STCSM 16JC1420500], Natural Science Foundation and Major Basic Research Program of Shanghai [16JC1420100], National Natural Science Foundation of China [81773513], Scientific Research Plan Project of Shanghai Science and Technology Committee [17411950701, 17411950106], Shanghai Municipal Science and Technology Major Project (No.2018SHZDZX01), ZHANGJIANG LAB, Tianqiao and Chrissy Chen Institute, and the State Key Laboratory of Neurobiology and Frontiers Center for Brain Science of Ministry of Education, Fudan University.

SPAH: the Wellcome Trust Foundation and FAPESP, São Paulo, Brazil;

ZARADEMP: Supported by grants from the Fondo de Investigación Sanitaria, Instituto de Salud Carlos III, Spanish Ministry of Economy and

Competitiveness, Madrid, Spain (grants 94/1562, 97/1321E, 98/0103, 01/0255, 03/0815, 06/0617, G03/128), and the Fondo Europeo de Desarrollo Regional (FEDER) of the European Union and Gobierno de Aragón, Group \#19. The sponsors were not involved in the design and conduct of the study; collection, management, analysis, and interpretation of the data; preparation, review, or approval of the manuscript; or decision to submit the manuscript for publication. The content is solely the responsibility of the authors and does not necessarily represent the official views of the National Institutes of Health or other funders.

\section{Availability of data and materials}

The datasets used and/or analyzed during the current study are available from the corresponding author on reasonable request.

\section{Ethics approval and consent to participate}

This study was approved by the University of New South Wales Human Research Ethics Committee (Ref: \# HC12446). Each of the 11 contributing studies had previously obtained ethics approval from their respective institutional review boards, and all participants provided informed consent.

\section{Consent for publication}

Not applicable

Competing interests

All authors declare no competing financial interests. 


\section{Author details}

'Department of Neuropsychiatry, Seoul National University Bundang Hospital, Seongnam, South Korea. ${ }^{2}$ Department of Psychiatry, College of Medicine, Seoul National University, Seoul, South Korea. ${ }^{3}$ Centre for Healthy Brain Ageing, University of New South Wales, Sydney, Australia. ${ }^{4}$ Dementia Collaborative Research Centre, University of New South Wales, Sydney, Australia. ${ }^{5}$ Department of Psychiatry, Yonsei University Wonju Severance Christian Hospital, Wonju, South Korea. ${ }^{6}$ Department of Psychiatry, Dongguk University Gyeongju Hospital, Gyeongju, South Korea. ${ }^{7}$ Department of Psychiatry, School of Medicine, Gyeongsang National University, Jinju, South Korea. ${ }^{8}$ Department of Neuropsychiatry, Soonchunhyang University Bucheon Hospital, Bucheon, South Korea. ${ }^{9}$ Department of Psychiatry, School of Medicine, Chungnam National University, Daejeon, South Korea. ${ }^{10}$ Department of Psychiatry, School of Medicine, Konkuk University and Konkuk University Chungju Hospital, Chungju, South Korea. ${ }^{11}$ Department of Neuropsychiatry, Jeju National University Hospital, Jeju, South Korea. ${ }^{12}$ Department of Psychiatry, School of Medicine, Konkuk University and Konkuk University Medical Center, Seoul, South Korea. ${ }^{13}$ Department of Neuropsychiatry, Kyunggi Provincial Hospital for the Elderly, Yongin, South Korea. ${ }^{14}$ Department of Neuropsychiatry, Seoul National University Hospital, Seoul, South Korea. ${ }^{15}$ Department of Neuropsychiatry, Inje University Sanggye Paik Hospital, Seoul, South Korea. ${ }^{16}$ Department of Psychiatry, Dankook University Hospital, Cheonan, South Korea. ${ }^{17}$ Department of Neuropsychiatry, Kangwon National University Hospital, Chuncheon, South Korea. ${ }^{18}$ Finlay-Albarrán Faculty of Medical Sciences, Medical University of Havana, Havana, Cuba. ${ }^{19}$ Institute of Neurology and Neurosurgery, Havana, Cuba. ${ }^{20}$ Medical University of Matanzas, Matanzas, Cuba. ${ }^{21}$ Memory and Aging Center, University of California San Francisco, San Francisco, CA, USA. ${ }^{22}$ Inserm U1061 Neuropsychiatry: Epidemiological and Clinical Research, La Colombière Hospital, Montpellier, France. ${ }^{23}$ Department of Clinical Brain Sciences, University of Edinburgh, Edinburgh, UK. ${ }^{24}$ Department of Psychiatry and Neurochemistry, Institute of Neuroscience of Physiology, Sahlgrenska Academy, Centre for Ageing and Health (AGECAP) at the University of Gothenburg, Gothenburg, Sweden. ${ }^{25} 1$ st Department of Neurology, Aiginition Hospital, National and Kapodistrian University of Athens, Medical School, Athens, Greece. ${ }^{26}$ Department of Neurology, Columbia University, New York, USA. ${ }^{27}$ Department of Nutrition and Dietetics, Harokopio University, Athens, Greece. ${ }^{28}$ Neurology Department, University Hospital of Larissa, University of Thessaly, Larissa, Greece. ${ }^{29}$ Geriatric Behavioral Neurology, Tohoku University, Sendai, Japan. ${ }^{30}$ Institute of Social Medicine, Occupational Health and Public Health (ISAP), Medical Faculty, University of Leipzig, Leipzig, Germany. ${ }^{31}$ Department of Psychiatry and Neuropsychology, School for Mental Health and Neuroscience (MHeNs), Maastricht University, Maastricht, Netherlands. ${ }^{32}$ Institute of Neurology, Huashan Hospital, Fudan University, Shanghai, China. ${ }^{33}$ National Clinical Research Center for Aging and Medicine, Huashan Hospital, Fudan University, Shanghai, China. ${ }^{34}$ University of São Paulo, São Paulo, Brazil. ${ }^{35}$ Universidad de Zaragoza, Zaragoza, Spain. ${ }^{36}$ Instituto de Investigación Sanitaria Aragón, Zaragoza, Spain. ${ }^{37}$ Biomedical Research Networking Center for Mental Health Network (CIBERSAM), Instituto de Salud Carlos III, Madrid, Spain. ${ }^{38}$ Department of Brain and Cognitive Science, Seoul National University College of Natural Sciences, Seoul, South Korea.

Received: 14 March 2020 Accepted: 19 June 2020

Published online: 05 August 2020

\section{References}

1. Winblad B, Amouyel P, Andrieu S, Ballard C, Brayne C, Brodaty H, CedazoMinguez A, Dubois B, Edvardsson D, Feldman H. Defeating Alzheimer's disease and other dementias: a priority for European science and society. Lancet Neurol. 2016;15(5):455-532.

2. Altmann A, Tian L, Henderson WW, Greicius MD, Investigators AsDNI. Sex modifies the APOE-related risk of developing Alzheimer disease. Ann Neurol. 2014;75(4):563-73.

3. Sinforiani E, Citterio A, Zucchella C, Bono G, Corbetta S, Merlo P, Mauri M. Impact of gender differences on the outcome of Alzheimer's disease. Dement Geriatr Cogn Disord. 2010;30(2):147-54.

4. Naftolin F, Silva I, Orley A. Reproductive Hormones and Dementia. In: Reproductive Medicine for Clinical Practice. 1st edn. Cham: Springer; 2018: 191-201.
5. Cunningham FG. Williams obstetrics 24th edition McGraw-Hill education. In: Medical; 2014.

6. Emechebe C, Njoku C, Eyong E, Maduekwe K, Ukaga J. The social class and reasons for grand multiparity in Calabar, Nigeria. Trop J Obstet Gynaecol. 2016;33(3):327-31.

7. Xu B, Chen Y, Xiong J, Lu N, Tan X. Association of female reproductive factors with hypertension, diabetes and LQTc in Chinese women. Sci Rep. 2017;7:42803.

8. Lawlor DA. Is the association between parity and coronary heart disease due to biological effects of pregnancy or adverse lifestyle risk factors associated with child-rearing?: findings from the British Women's Heart and Health Study and the British Regional Heart Study. Circulation. 2003;107(9): $1260-4$.

9. Nicholson WK, Asao K, Brancati F, Coresh J, Pankow JS, Powe NR. Parity and risk of type 2 diabetes: the atherosclerosis risk in communities study. Diabetes Care. 2006;29(11):2349-54.

10. Jang H, Bae JB, Dardiotis E, Scarmeas N, Sachdev PS, Lipnicki DM, Han JW, Kim TH, Kwak KP, Kim BJ. Differential effects of completed and incomplete pregnancies on the risk of Alzheimer disease. Neurology. 2018;91 (7):e643-51.

11. Ptok U, Barkow $K$, Heun R. Fertility and number of children in patients with Alzheimer's disease. Arch Womens Ment Health. 2002;5(2):83-6.

12. Baldereschi M, Di Carlo A, Lepore V, Bracco L, Maggi S, Grigoletto F, Scarlato G, Amaducci L. Estrogen-replacement therapy and Alzheimer's disease in the Italian Longitudinal Study on Aging. Neurology. 1998;50(4):996-1002.

13. Gilsanz P, Corrada MM, Kawas CH, Quesenberry CP, Lee C, Whitmer RA. Women's reproductive history and dementia risk. Alzheimers Dement. 2018; 14(7):P1350-1.

14. Sachdev PS, Lipnicki DM, Kochan NA, Crawford JD, Rockwood K, Xiao S, Li J, Li X, Brayne C, Matthews FE. COSMIC (Cohort Studies of Memory in an International Consortium): an international consortium to identify risk and protective factors and biomarkers of cognitive ageing and dementia in diverse ethnic and sociocultural groups. BMC Neurol. 2013;13(1):165.

15. Llibre-Rodríguez JJ, Valhuerdi-Cepero A, López-Medina AM, NoriegaFernández L, Porto-Álvarez R, Guerra-Hernández MA, Bosch-Bayard Rl, ZayasLlerena T, Hernandez-Ulloa E, Rodríguez-Blanco AL. Cuba's aging and Alzheimer longitudinal study. MEDICC Rev. 2017;19:31-5.

16. Ritchie K, Carrière I, Ritchie C, Berr C, Artero S, Ancelin M-L. Designing prevention programmes to reduce incidence of dementia: prospective cohort study of modifiable risk factors. BMJ. 2010;341:C3885.

17. Thorvaldsson V, Karlsson P, Skoog J, Skoog I, Johansson B. Better cognition in new birth cohorts of 70 year olds, but greater decline thereafter. J Gerontol B Psychol Sci Soc Sci. 2017;72(1):16-24.

18. Dardiotis E, Kosmidis MH, Yannakoulia M, Hadjigeorgiou GM, Scarmeas N. The Hellenic Longitudinal Investigation of Aging and Diet (HELIAD): rationale, study design, and cohort description. Neuroepidemiology. 2014; 43(1):9-14.

19. Han JW, Kim TH, Kwak KP, Kim K, Kim BJ, Kim SG, Kim JL, Kim TH, Moon SW, Park JY et al: Overview of the Korean Longitudinal Study on Cognitive Aging and Dementia. Psychiatry Investig. 2018;15(8):767-74.

20. Kumai K, Meguro K, Kasai M, Nakamura K, Nakatsuka M. Neuroepidemiologic and neurobehavioral characteristics of motoric cognitive risk syndrome in an old-old population: the Kurihara project. Dement Geriatr Cogn Disord Extra. 2016;6(2):176-82

21. Riedel-Heller SG, Busse A, Aurich C, Matschinger H, Angermeyer MC. Prevalence of dementia according to DSM-III-R and ICD-10: results of the Leipzig Longitudinal Study of the Aged (LEILA75+) part 1. Br J Psychiatry. 2001;179(3):250-4

22. Jolles J, Houx P, Van Boxtel M, Ponds R. The Maastricht Aging Study. Determinants of cognitive aging Maastricht. 1995;192.

23. Ding D, Zhao Q, Guo Q, Meng H, Wang B, Yu P, Luo J, Zhou Y, Yu L, Zheng $L$, et al. The Shanghai Aging Study: study design, baseline characteristics, and prevalence of dementia. Neuroepidemiology. 2014; 43(2):114-22.

24. Scazufca M, Menezes PR, Araya R, Di Rienzo VD, Almeida OP, Gunnell D, Lawlor DA, Sao Paulo A, Health S. Risk factors across the life course and dementia in a Brazilian population: results from the Sao Paulo Ageing \& Health Study (SPAH). Int J Epidemiol. 2008;37(4):879-90.

25. Lobo A, Lopez-Anton R, Santabarbara J, de-la-Cámara C, Ventura T, Quintanilla M, Roy J, Campayo A, Lobo E, Palomo T. Incidence and lifetime risk of dementia and Alzheimer's disease in a Southern European population. Acta Psychiatr Scand. 2011;124(5):372-83. 
26. American Psychiatric Association: Diagnostic and statistical manual of mental disorders. 1994.

27. American Psychiatric Association: Diagnostic and Statistical Manual of Mental Disorders, 3rd ed., revised (DSM-III-R). Washington, D.C.: American Psychiatric Association; 1987.

28. McKhann G, Drachman D, Folstein M, Katzman R, Price D, Stadlan EM. Clinical diagnosis of Alzheimer's disease report of the NINCDS-ADRDA Work Group* under the auspices of Department of Health and Human Services Task Force on Alzheimer's Disease. Neurology. 1984;34(7):939.

29. Román GC, Tatemichi TK, Erkinjuntti T, Cummings JL, Masdeu J, Ja G, Amaducci L, Orgogozo J-M, Brun A, Hofman A. Vascular dementia diagnostic criteria for research studies: report of the NINDS-AIREN International Workshop. Neurology. 1993;43(2):250.

30. Margioti E, Kosmidis MH, Yannakoulia M, Dardiotis E, Hadjigeorgiou G, Sakka P, Ntanasi E, Vlachos GS, Scarmeas N. Exploring the association between subjective cognitive decline and frailty: the Hellenic Longitudinal Investigation of Aging and Diet Study (HELIAD). Aging Ment Health. 2020; 24(1):137-47.

31. Mishra GD, Pandeya N, Dobson AJ, Chung HF, Anderson D, Kuh D, Sandin S, Giles GG, Bruinsma F, Hayashi K, et al. Early menarche, nulliparity and the risk for premature and early natural menopause. Hum Reprod. 2017;32(3): 679-86

32. Gilsanz P, Lee C, Corrada MM, Kawas CH, Quesenberry CP, Jr., Whitmer RA: Reproductive period and risk of dementia in a diverse cohort of health care members. Neurology 2019;92(17):e2005-e2014.

33. Babinszki A, Kerenyi T, Torok O, Grazi V, Lapinski RH, Berkowitz RL. Perinatal outcome in grand and great-grand multiparity: effects of parity on obstetric risk factors. Am J Obstet Gynecol. 1999;181(3):669-74.

34. Khwaja H, Syed H, DJBi C. Coding errors: a comparative analysis of hospital and prospectively collected departmental data. BJU Int. 2002;89(3):178-80.

35. Loriaux DL, Ruder H, Knab D, Lipsett M. Estrone sulfate, estrone, estradiol and estriol plasma levels in human pregnancy. J Clin Endocrinol Metab. 1972;35(6):887-91.

36. Sudo S, Wen T-C, Desaki J, Matsuda S, Tanaka J, Arai T, Maeda N, Sakanaka M. $\beta$-Estradiol protects hippocampal CA1 neurons against transient forebrain ischemia in gerbil. Neurosci Res. 1997;29(4):345-54.

37. Hoekzema E, Barba-Muller E, Pozzobon C, Picado M, Lucco F, Garcia-Garcia D, Soliva JC, Tobena A, Desco M, Crone EA, et al. Pregnancy leads to longlasting changes in human brain structure. Nat Neurosci. 2017;20(2):287-96.

38. Haim A, Julian D, Albin-Brooks C, Brothers HM, Lenz KM, Leuner B. A survey of neuroimmune changes in pregnant and postpartum female rats. Brain Behav Immun. 2017;59:67-78.

39. Munro CJ, Stabenfeldt G, Cragun J, Addiego L, Overstreet J, Lasley B. Relationship of serum estradiol and progesterone concentrations to the excretion profiles of their major urinary metabolites as measured by enzyme immunoassay and radioimmunoassay. Clin Chem. 1991;37(6):83844.

40. Chavez-MacGregor M, van Gils CH, van der Schouw YT, Monninkhof E, van Noord PA, Peeters PH. Lifetime cumulative number of menstrual cycles and serum sex hormone levels in postmenopausal women. Breast Cancer Res Treat. 2008;108(1):101-12.

41. Prince M, Guerchet M, Prina M: The global impact of dementia 2013-2050. London: Alzheimer's Disease International; 2013.

42. United Nations: World population prospects: 2019. In., vol. 145: United Nations; 2019

43. Arslan AA, Zeleniuch-Jacquotte A, Lukanova A, Afanasyeva Y, Katz J, Levitz $M$, Del Priore $G$, Toniolo P. Effects of parity on pregnancy hormonal profiles across ethnic groups with a diverse incidence of breast cancer. Cancer Epidemiol Biomark Prev. 2006;15(11):2123-30.

44. Ghosh G, Grewal J, Mannisto T, Mendola P, Chen Z, Xie Y, Laughon SK. Racial/ethnic differences in pregnancy-related hypertensive disease in nulliparous women. Ethn Dis. 2014;24(3):283-9.

45. Humphries KH, Westendorp IC, Bots ML, Spinelli JJ, Carere RG, Hofman A, Witteman JC. Parity and carotid artery atherosclerosis in elderly women: the Rotterdam study. Stroke. 2001;32(10):2259-64.

46. Koropeckyj-Cox T, Call VRA: Characteristics of Older Childless Persons and Parents: Cross-National Comparisons. J Fam Issues. 2007;28(10):1362-414.

47. Barbieri RL: Female infertility. In: Yen and Jaffe's Reproductive Endocrinology. 8th edn. Philadelphia: Elsevier; 2019:556-81.
48. Ryan J, Scali J, Carriere I, Amieva H, Rouaud O, Berr C, Ritchie K, Ancelin ML. Impact of a premature menopause on cognitive function in later life. BJOG. 2014;121(13):1729-39.

49. Goodman C, Goodman CS, Hur J, Jeyendran RS, Coulam C. The association of Apoprotein E polymorphisms with recurrent pregnancy loss. Am J Reprod Immunol. 2009;61(1):34-8.

\section{Publisher's Note}

Springer Nature remains neutral with regard to jurisdictional claims in published maps and institutional affiliations.

\section{Ready to submit your research? Choose BMC and benefit from:}

- fast, convenient online submission

- thorough peer review by experienced researchers in your field

- rapid publication on acceptance

- support for research data, including large and complex data types

- gold Open Access which fosters wider collaboration and increased citations

- maximum visibility for your research: over $100 \mathrm{M}$ website views per year

At BMC, research is always in progress.

Learn more biomedcentral.com/submissions 